\title{
A HISTÓRIA DA COCAÍNA EM BENJAMIN CONSTANT
}

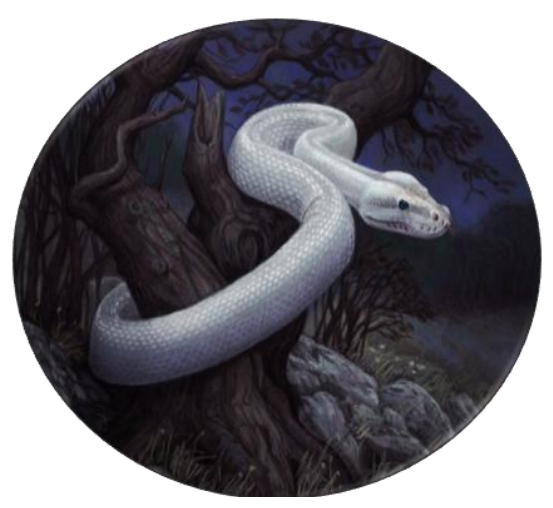

Ricardo Barbosa Moraes

\begin{abstract}
Resumo
O texto trata da história da cocaína e da genealogia do poder ecológico. A cocaína torna-se uma peça de poder político quando se estabeleceu o interesse pela matéria-prima da cocaína da Amazônia foi o momento do isolamento do principio ativo da cocaína, tornando-se objeto do conhecimento médico e filosófico do século XIX. No século XX, com declínio da produção da borracha e com a entrada da cocaína na cultura de massa das cidades Ocidentais, a visibilidade da economia da cocaína cruza o caminho da ética puritana, sem mais prejuízos, porque o teatro cristão, o hábito reiterado da cocaína é mais um meio da política de controle da vida do governo americano, que ao estabelecer o controle político do mercado da cocaína está simplesmente ampliando o domínio da sustentabilidade pelo poder ecológico em controlar os recursos naturais da Amazônia, na forma de uma grande colônia do século XXI.
\end{abstract}

Palavras-chave: Cocaína. Poder. Ecopolítica. Amazônia.

\begin{abstract}
The text deals with the history of cocaine and the genealogy of ecological power. Cocaine becomes a piece of political power when the interest in the Amazonian cocaine raw material was established, it was the moment of isolation of the active principle of cocaine, becoming object of the medical and philosophical knowledge of the nineteenth century. In the twentieth century, with the decline of rubber production and the entry of cocaine into the mass culture of Western cities, the visibility of the cocaine economy crosses the path of Puritan ethics without further harm because Christian theater, the cocaine is another means of US government life control policy which, by establishing political control of the cocaine market, is simply broadening the domain of sustainability by ecological power to control the natural resources of the Amazon in the form of a large colony of XXI century.
\end{abstract}

Keywords: Cocaine. Power. Ecopolytic. Amazon. 
A manifestação do poder na história da cocaína na cidade de Benjamin Constant torna-se uma peça política na expansão e ocupação do Trapézio Amazônico através da economia da borracha e da economia da cocaína. Com a decadência da produção da borracha, a economia da cocaína consolida um tipo de poder através da produção, comercialização e consumo do alcaloide da coca que interfere na política e na economia mundial, como objeto do conhecimento científico-médico, filosófico, econômico, criminológico e penal desde o século XIX ao século XXI. A entrada da cocaína na cultura de massa das cidades Ocidentais pelo emblemático hábito reiterado é mais um meio da política de controle de ampliar o domínio sobre os recursos da Amazônia, que chamo de poder ecológico o avanço e ocupação do território e da população pelo controle político, econômico e militar dos recursos sustentáveis, na síntese dessas relações, a ilegalidade do contrabando da cocaína é apenas uma peça da governamentalidade sustentável.

NIETZSCHE (1991) faz o diagnóstico do poder Ocidental, ligado ao conhecimento, à ciência, à política e ao estado. A genealogia de Nietzsche e Foucault aponta o momento do nascimento, do exercício e da morte do poder, embora não sendo uma entidade tempo-espacial, o poder marca sua individualidade no cenário histórico Ocidental. Em Vigiar e Punir (2010) encontra-se o pátrio poder dos romanos, o poder soberano do Antigo Regime, a microfísica do poder disciplinar, na História da Sexualidade (1988), o poder de vida e de morte, o biopoder; no Nascimento da Biopolítica (2008), o poder do governo, ou seja, o poder da governamentalidade americana, PASSETTI (2002) fala do poder da ecopolítica, MALETTE (2011) da racionalidade ecológica. Dentro desse marco construo a ideia do poder ecológico.

Utilizo a ideia de MALETTE (2011) para pensar o poder ecológico a partir do conceito de governamentalide de Foucault, para refletir as maneiras de modelar, administrar, regular a conduta da humana, 
conjugada com a problemática da exploração da natureza tal como tem sido delineada na história da Amazônia durante os três últimos séculos. Nessa linha, afirmo que a genealogia da cocaína aponta para o poder ecológico da Amazônia.

o trabalho de Foucault sobre a governamentalidade - e mais particularmente seu conceito de biopolítica _ pode ser reconstruído como o estudo da 'ecopolíca' quando as condições sob as quais populações são administradas estão subordinadas a tentativas mais amplas de administrar toda a Vida com o desdobramento de racionalidades ecológicas de governo (p. 11-12).

A constatação do poder ecológico segundo PASSETTI (2002) e MALETTE (2011) pressupõe uma mudança na análise da biopolítica para a ecopolítica que pode ser sustentada pela expansão da genealogia do poder de Michel Foucault.

Segundo MALETTE (2011), o conceito governamentalidade neoliberal pautada nos conceitos de população, segurança e economia política do pensamento de Michel Foucault, com a racionalidade ecológica o conceito se expande para regulação de tudo que é vivo. Nessa perspectiva, para PASSETTI (2002), as relações de poder posta na ecopolitica é um acontecimento planetário da sociedade de controle.

O trabalho de Foucault é de importância central nas análises da produção e circulação de saber, tecnologias e racionalidade de governo que recorrem a noções de "natureza". Mas precisamente, as amplamente disseminadas ecogovernamentalidade e as tecnologias ambientais são vistas como extensões das redes disciplinares, descrita por Foucault em Vigiar e Punir, e $\mathrm{da}$ biopolítica que o interessa em seus trabalhos posteriores. Assim, seu conceito de biopolítica é ampliado para incluir tudo o que seja necessário para manter a 'vida' pela emergência de diversas práticas e regulações ambientais (MALETTE, p. 10). 
Segundo PASSETTTI (2002), a ecopolítica enfrenta os dilemas do tipo da centralização Estado, controle dos indivíduos, normalização da conduta humana, investimentos na população pobre, etnias e culturas; utilização de pessoas, como as crianças, os velhos, os doentes e homossexuais; os modos de investimentos e produção do corpo, da biodiversidade e da qualidade e longevidade da vida.

Segundo PASSETTI (2002), esses são temas complexos que exigem outra metodologia de conhecimento, por isso Foucault renunciava a abordagem de uma teoria do sujeito de conhecimento em que o sujeito da observação tem um papel construtor da historicidade, capaz de pensar as condições políticas e jurídicas em termos de progresso e de educação da humanidade. Para ele, o paradigma do iluminismo, que serve de fundamento moral do direito penal moderno, não é mais capaz de pensar as novas formas do crime do castigo, em espacial ao tange ao mercado da economia da cocaína.

A cocaína deixa de ser um problema de saúde pública e de segurança nacional, com restrições de governos nacionais, tal como prevista pela legislação antidrogas e entra em um regime internacional planetário, com procedências ao meio ambiente e a preservação do planeta e da humanidade.

A história da cocaína pode ser construída pela manifestação de três tipos de poder: o poder ecológico relacionado ao controle político da matéria-prima da cocaína. O poder disciplinar relacionado à elaboração da delinquência e da dependência química. A biopolítica relacionada à política de racionalidade de controle da vida. Os três tipos de poder estão correlacionados em torno de uma política de controle planetário dos recursos sustentáveis da Amazônia. No momento escrevo apenas sobre o poder ecológico.

A genealogia do poder ecológico está relacionada aos processos de ocupação humana e exploração dos recursos sustentáveis da Amazônia que 
teve inicio com a colonização europeia no século XVI, marcado com conflitos entre os povos originários e os europeus, em especial, os portugueses e espanhóis e entre eles pela posse do território do Trapézio Amazônico, continuada com os estados nacionais em meados do século XIX através do extrativismo da coca e da borracha, com a decadência da produção da borracha no inicio século XX, a economia da cocaína vai predominar até o século XXI através da presença do que podemos chamar de brasileiros, colombianos e peruanos entre outros.

Em 1755, os jesuítas fundam a aldeia do Javari para reunir índios ticuna. O governo português cria a capitania de São José do Rio Negro, com a sede na aldeia do Javari que recebe o nome de São José do Javari.

A aldeia do Javari representou a consolidação da ocupação brasileira da região do Alto Solimões, sobretudo os interflúvios dos altos cursos dos afluentes do rio Solimões, especialmente aqueles que ocorrem no interior do trapézio amazônico. A aldeia do Javari é antecedente à fundação da cidade de Benjamin Constant. Segundo MELLO (1967), a vila recebe o nome de São José do Javari por Carta Régia de Dom José I, de Portugal, a fim de ser instalada a capital da Capitania de São José do Rio Negro.

A presença populacional dos indos Omágua indica que a colonização não se realizou em espaço vazio, ao contrário, no centro da disputa política pelo território e pelos recursos sustentáveis está o colonizador espanhol e os povos indígenas, ocupantes originais.

O processo de redução dos Omágua vai predominar até o século XVIII, quando são "substituídos por aqueles deslocados para os aldeamentos missionários que se espalharam de leste a oeste, ocasionando uma grande mudança na composição étnica e cultural das várzeas amazônicas" (COSTA, 2009, p. 6).

Do século XVIII ao XIX houve um deslocamento populacional dos índios Ticuna às margens do rio Solimões, acentuando a urbanização 
da cidade de Benjamin Constant. O processo de urbanização do interior do Amazonas é genuíno da expansão colonial da exploração da borracha, quando o capital internacional, por meio dos donos dos seringais utilizavam os índios como força de trabalho.

O poder ecológico ou a política de controle da sustentabilidade amazônica na sua forma espanhola e portuguesa agiu basicamente em relação trabalho indígena compulsório, a pesca, a caça, a lavoura, coleta de produtos como o cacau, o cravo, a quina, a salsaparrilha, a coca, a seringa entre outros. Essa situação perdurou por todo o período colonial e em grande parte do século XIX, chegando mesmo a conservar essas características com extrativismo da borracha e a produção da cocaína.

O comércio ilegal foi um meio do poder ecológico de consolidar o controle dos meios sustentáveis. Segundo COSTA (2009), os colonizadores utilizaram das rivalidades das tribos indígenas para comercializar prisioneiros capturados em guerra, mulheres e crianças raptadas de tribos inimigas trocadas com alimentos, tecidos, utensílios, meio pelo qual suprima a necessidade de mão de obra escrava.

A incorporação dos índios á sociedade colonial se deu, frequentemente, por meio de três estratégias que, muitas vezes, andaram juntas: a violência física (guerras, escravização, punições etc.); as alianças para o intercâmbio de bens ou para a guerra, construídas entre colonizadores e diferentes povos indígena - o que explica, por exemplo, que as expedições portuguesas de conquista ao longo dos rios amazônicos fossem majoritariamente compostas por índios armados; e, ainda, a conversão ao cristianismo, por meio da atuação de diversas ordens religiosas (COSTA, 2009, p. 7-8).

$\mathrm{Na}$ entrada do século XX, a cidade de Benjamin Constant é palco da racionalidade do poder ecológico da econômica borracha. O controle político do látex é uma ecopolítica que se constituiu na Amazônia na forma 
de uma governamentalidade dos meios ambientais, das tecnologias de poder e das racionalidades de governo.

A política de controle dos recursos sustentáveis vai constituir novas relações de controle na expansão do território, impondo novos mecanismos de poder sobre as relações de trabalho que doravante vai reeditar o controle da população pela força física, pela punição e pela, não sob o poder soberano do espanhol e do português, mas pelas relações de poder da racionalidade ecológica sob o comando dos novos personagens do trapézio, os brasileiros, os colombianos, os peruanos, motivados pelos os estados nacionais.

O extrativismo da folha da coca e a cultura da mastigação do fumo e da inalação do pó ainda hoje é parte fundamentação de alguns povos dos países amazônicos.

No norte do Brasil, também é chamada de epadu. Muitas tribos da Bacia Amazônica, na região fronteiriça entre Venezuela, Colômbia e Brasil, mantêm o hábito de marcar o 'epadu' ou 'ipadu' como forma de preparo das folhas torradas de coca misturadas com elementos alcalinos, transformadas em pó e agrupadas em pequenas bolinhas. Os homens e as mulheres mais idosos, principalmente da tribo dos Tucanos, ingerem o pó várias vezes ao dia, utilizando colheres de osso. Além do valor nutritivo, esses indígenas buscam o bemestar e a ação euforizante que fazem parte do seu cotidiano (FERREIRA \& MARTINI, 2001, p. 96-97).

Até o século XIX, a produção da coca é insipiente, tem o objetivo de abastecer o consumo local, funciona como uma cultura de subsistência integrante da dieta regular da economia doméstica de alguns agricultores do Alto Solimões, ainda muito tímida ante a economia da borracha. A Europa importa coca dos Andes peruanos para a produção de bebidas e fabricação de remédios. Na entrada do século XX Freud é um dos primeiros a divulgar a cocaína no meio acadêmico mas também é o momento do acontecimento singular na história do alcalóide da coca, a entrada da 
cocaína na história das drogas pela proibição moral e legal americana, de cujo espírito é a construída a legislação brasileira antidroga.

Neste momento, no inicio do século XX, a economia da cocaína ainda não tem nenhuma relação com Benjamin Constant que vive do extrativismo da borracha. Segundo JOBIM (1943), em 1903 quando a produção da borracha alcançou nível elevado, a população Benjamin Constant cresceu, chegando 20.000 habitantes. Esse crescimento está relacionado às secas no Nordeste brasileiro que emburra milhares de pessoas para trabalhar nos seringais.

Segundo SOUZA (2009), a economia da Borracha, "da humilde origem em 1870 o extrativismo da borracha ocupou em 1910 um quarto da exportação brasileira" (p. 236). Segundo JOBIM (1934), na cidade de Benjamin Constant, a goma elástica era o principal artigo de exportação, sua fonte de receita. A cidade possuía um movimento de dinheiro, faziamse excelentes negócios. Os vapores chegavam cheios de mercadorias e saiam carregados de produtos.

Segundo COSTA (2009), no princípio, o látex teve apenas uso local na impermeabilização de roupa e calçado, no advento da vulcanização, o látex entra produção industrial, cuja demanda mundial aumentou a "ponto de ocasionar um boom comercial que durou cerca de 70 anos e alcançou, com diferente intensidade, todos os países amazônicos então independentes" (p. 13).

O poder ecológico agiu na racionalidade do látex na forma de um governo na administração dos recursos sustentáveis da floresta e na administração da população composta de cristãos católicos, missionários, comerciantes de todos os tipos, mais em especial o comércio do aviamento, moradores da região ou de outras nacionalidades, adicionou ao ambiente amazônico uma parte significativa da população nordestina submetida aos domínios do coronel da borracha; 
O controle político do látex pela exploração do trabalho indígena encontrou resistência pelo ticuna e pelos índios do rio Javari que não cederam ao interesse de submetê-los como mão de obra barata e como trabalho escravo, mais de um modo geral, manteve relação de confronto com a população indígena, com o interesse de submetê-los como mão de obra barata e como trabalho escravo.

O foco do poder ecológico não se encontra mais na fronteira de uma população, de uma cidade, muito menos de uma comunidade, por fim, não se trata de uma instituição ou daquele governo em particular, espaço do exercício do poder disciplinar e da biopoder, mas se encontra da fronteira de um governo continental, direcionado para os fenômenos de mercado, que ultrapassa a fronteira da população de um país, e capta forças históricas e tensões internacionais.

A política da racionalidade ecológica é permeada pela variedade de cultura, língua e costumes, perpassada e permeada pelos fatores pelo ambiente natural constituiu uma síntese entre o humano e natural, que chamamos de homem amazônico que nada mais é do que o exercício do poder ecológico em habilitar populações inteiras a determinado regime de governo de que podemos chamar de sustentável. Segundo SOUZA (2009), o poder amazônico pode ser descrito no Relato de um certo oriente de Milton Hatoum.

Assim é a identidade da Amazônia. Um corpo formado pelos rios enorme, pelas selvas brutalmente dilaceradas, pelos povos indígenas dizimados, pela saga dos homens pela conquista da natureza. Mas ao mesmo tempo não deixa de estar perenemente voltada para Meca, que é a própria Amazônia, um espaço tão vasto quanto a crença, capaz de fazer a geografia confluir para pedra negra que dentro de nós indica que somos da Amazônia, filhos da mata, filhos das águas ( p.18).

A racionalidade ecológica do látex levou a economia da Amazônia a momentos de bonanças e momentos de crise, alternando o sentido da 
cultura, da arquitetura e da moral, mais em especial carrega consigo como uma sombra todo o peso da ilegalidade do contrabando da borracha e da incapacidade de adaptar as circunstâncias da floresta amazônica.

Os armazéns que se localizavam na região do trapézio compravam a borracha de Benjamin Constant. Com a crescente exploração dos seringais do Javari, Benjamim Constant passa a ser um centro comercial, atraindo os grandes capitais. $\mathrm{O}$ valor menor e a facilidade da tarifa aduaneira peruana na fronteira proporcionavam ao contrabando da borracha brasileira.

O comerciante encontrava vantagens em vender a borracha no Peru, pela facilidade de transportá-la para a outra margem, aproveitando-se da diferença sobre tarifas. As mercadorias dos armazéns peruanos eram vendidas por preço inferior aos da sua vizinha brasileira. A transferência da borracha para o Peru, por via ilegal, era realizada por um valor inferior às transações legais, o que favorecia a saída da goma proveniente do Peru. Segundo JOBIM (1943), a produção "era desviada e embarcada como de procedência daquele país. A nossa borracha desnacionalizava-se, e era vendida como oriunda dos seringais do Marañon e Maina” (p. 173-180).

O contrabando da borracha cresceu de tal maneira, que os perniciosos efeitos se fizeram sentir pelo governo brasileiro. Tornou-se visível o declínio da borracha da margem brasileira do Javari, do rio Juruá e Solimões, que deviam aumentar a produção o que não sucedeu.

A borracha desviada para o Peru provocou um prejuízo para as rendas estaduais, enquanto aumentava a renda de Iquitos. O produto era exportado como de origem peruana. Segundo JOBIM (1934), em 1904, Francisco Benedito da Fonseca Coutinho, vice-governador do Estado, em exercício, tinha plena consciência da ilegalidade visível na fronteira:

Extensa, como é a nossa fronteira com a república do Peru, mais difícil se torna, pelas condições especiais do Javari, o exercício de uma fiscalização regular e perfeita, de forma a impedir o transporte de gênero brasileiro para a margem da República limítrofe, onde a 
benignidade excessiva dos direitos de exportação concita ao contrabando (p. 174).

O discurso do funcionário público, Pedro Bandeira, da Coletoria de Rendas do Javarí, escrevia em 1901, sobre o contrabando dos rios afluentes do rio Javari:

O curso do rio Javarí, longo e sinuosíssimo, dispõe de três tributários que nele desaguam pela margem direita, rasgando em não pequena extensão o território nacional, sendo o menor deles o rio Santana, que fica mais distante dos pontos fiscais. Seguindo-se depois o rio Curuçá, finalmente o maior deles o rio Itecoaí, que desagua em pouco mais perto da confluência do Javarí com o Solimões. O primeiro dos três rios não possui fiscalização alguma; o segundo, apesar de ter a vigilância de um coletor e dois guardas, nem por isso deixa de sofrer o mal do contrabando, por engano ou logro dos sindicatos. O terceiro, finalmente não obstante estar sob a inspeção direta do chefe desta Coletoria, não oferecendo imunidade àquela enfermidade, que arruína surda e violentamente, graças às comunicações que entretém, em vários pontos distantes de sua foz com o próprio rio Javarí, por meio de varadouros ou desaguadouros dos lagos das terras intermediárias, os quais estabelecem, por ocasião das cheias, franeas passagens, tanto a canoa, como até lanchas a vapor (JOBIM, 1943, p. 179).

Segundo JOBIM (1943), a população de Benjamin Constant em 1903 reduziu para maios ou menos 10.000 habitantes a desvalorização da borracha e logo desapareceu a atividade do contrabando borracha.

A queda do preço da borracha amazônica tornou-se irreversível, sem poder concorrer com seu similar asiático. Vai ser acompanhada com a metamorfose do poder ecológico do látex relacionado à falência de capital na região, desativação de linha de transportes, abandono da região, fechamento de casas comerciais, redução da população e desaparecimento de vilas. As relações de poder do látex criaram raízes com a ilegalidade do contrabando da borracha, ultrapassando a fronteira dos países amazônicos 
entrando na história das tensões internacionais, entra em crise e morre e logo renasce pela racionalidade ecológica da matéria-prima da cocaína.

O sistema extrativista empurrou milhares de trabalhadores para regiões distantes da Amazônia, invadiu terras indígenas, assegurou a posse de territórios para os Estados nacionais. Gerou uma elite frágil e subserviente que seria pasto fácil para as novas opções econômicas que estavam por vir (SOUZA, p.297).

No inicio do século XX, o aparato do Estado, a Polícia Militar, a Polícia Federal e o Exército ainda não estão instalados na cidade Benjamin Constant, a ilegalidade do contrabando de cocaína ainda não determina o nível da criminalidade do Alto Solimões. O crime e o castigo ainda são contornados pela norma consuetudinária. Fora o contrabando da borracha, ilegalidade da madeira na cidade de Benjamin Constant tem uma peculiaridade singular e uma dinâmica própria dentre outras infrações.

Segundo LEONARDI (2000), com estagnação da economia da borracha nos anos 40 tem inicio a economia extrativista da madeira no rio Javari, igualmente aconteceu no rio Jutaí e Jandiatuba. A entrada de madeireiros em terras indígenas ocasionou vários conflitos armados com os índios até os anos 50. Nos anos 70, a Petrobrás começou a fazer trabalhos de pesquisa e prospecção de petróleo e gás natural, o que provocou novos e sérios conflitos armados, com mortes de ambos os lados. Só então a Funai começou atuar no Javari, estreitando o contato com os Marubo, Kanamarí e Kulina (Pano) e promovendo a atração dos Matís, que foram finalmente contatados.

A cidade de Atalaia do Norte está localizada à margem direita abaixo do Rio Javari, ligada a Benjamin Constant pela Perimetral Norte. O isolamento do vale do Javari, nove dias de viajem de Atalaia do Norte até os índios Mayorúna do Igarapé Lobo, cuja distância do centro urbano cria uma mentalidade de rejeição em relação às Leis do Estado, “como se o 
isolamento amazônico lhe garantisse uma espécie de direito de extraterritorialidade" (LEONARDI, 2000, p, 119) de vender madeira para os peruanos sem pagar imposto e pagar um preço irrisório para índios que derrubam e carregam as toras de madeira, direito se armar contra os órgãos governamentais que nos anos 90 tentaram legalizar a extração da madeira. Mais evidente é nos locais remotos, a lei é feita por aqueles onde a acumulação pela força tem raízes históricas.

Segundo LEONARDI (2000), a maior fonte de renda legal de Benjamin Constant é da extração de madeira, que está localizada em grande parte de sua extensão geográfica em territórios indígenas. Nos anos 40 e 50 o beneficiamento da madeira era feito em Manaus. Nos anos 70 estavam instaladas duas serrarias em funcionamento no Solimões e no Javari. Duas serrarias elétricas na cidade Atalaia do Norte e quatro no Peru na fronteira de Benjamin Constant. "Como a fiscalização era mínima, uma parte da madeira contrabandeada e não gerou benefício algum para o Estado e para a população regional, a não ser para aqueles empresários praticam o contrabando" (p, 118-119).

Atividade madeireira no inicio foi muito mais intensa na região do que atualmente, com a forte pressão do órgão ambiental sobre a extração da madeira em área indígena, a atividade diminui muito, passando para o lado do rio, no Peru, que absorve trabalhadores brasileiros, e na Colômbia, onde é mais controlada. Além disso, a estruturação da rede transporte fluvial, seja com destinos a Iquitos, subindo o rio Solimões, seja com destino ao mercado europeu e americano, descendo em navio o rio Solimões, passando pelo rio Amazonas até Belém, ou ao centro do território colombiano pelo rio Putumayo e pela região brasileira pelo rio Iça, contribui com a diminuição do movimento madeireiro de Benjamin Constant.

O auge da atividade madeireira, ano de 1987 e 1992, os madeireiros extraíam madeira com ajuda dos índios e com o consentimento 
da Funai. Os madeireiros subiam as cabeceiras dos rios do vale do Javari, em terras indígenas, derrubavam as árvores e transportavam (desciam) na forma de torra, na época da enchente, pelos igarapés até os rios das cidades de Atalaia do Norte e Benjamin Constant.

Denunciados pela Funai em 1995-1996, os órgãos federais como o Ibama, a Policia Federal, o Exército e a própria Funai começaram a exercer um controle sobre a extração da madeira. Houve muitas apreensões de madeiras ilegais, gerando descontentamento geral entre empresários, inclusive aqueles que eram financiados por bancos oficiais, deixando muitos trabalhadores desempregado.

Sem levar em conta a ilegalidade da madeira, os conflitos mais comuns estavam relacionados à divisão de terras, à demarcação, à desavença entre vizinhos, julgamentos sobre a vida alheia; fatos singelos ou de valores consuetudinários que constituíam em processos circunscritos no cartório da cidade.

Além desses conflitos minúsculos de caráter moral, pode também ser encontrado um corpo institucional e jurídico, com características de mando e obediência, conduzidos pelos proprietários latifundiários, cujos personagens são comuns, como o coronel, o cabo eleitoral, o compadre, o afilhado, o chefe político, o seringalista, o regatão, o pescador, o aviador e fatos relacionados à perseguição aos inimigos e adversários políticos.

Dessa miscelânea de beligerância, alguns chegam às delegacias e até aos juízes, do mais, a cidade não propicia a generalização da doença mental, quando há, é insipiente, pode-se contar a dedo. Segundo ARAÚJO (2003), a prostituição, do mesmo modo, é silenciosa e tímida; quase não mostra a cara na cidade, o contrário, é a reincidência da criminalidade infanto-juvenil é perceptível na delegacia da cidade. Essa criminalidade simples vai suplantada pelo tráfico de cocaína, contemporâneo dos acontecimentos políticos da implantação dos projetos de segurança nacional na fronteira amazônica. $\mathrm{O}$ avanço da economia continental da 
cocaína na cidade de Benjamin Constant vai acionar os mecanismos de controle político do governo federal, para garantir a segurança da fronteira brasileira, mudando a fisionomia do crime e do castigo no Alto Solimões.

A política de controle da cocaína é parte de uma política de controle dos recursos sustentáveis da Amazônia, cujo interesse não se restringe ao poder de um governo em particular, mais se expande para a grande política de controle do recurso ecológico planetário que chamamos de poder ecológico porque tem o interesse do domínio de fonte de energia do planeta e das pessoas, cada vez mais expande o poder de controlar a matéria rara do ouro, dos minérios, do petróleo, do gás, da madeira, da biodiversidade da floresta, da água e da alimentação e da própria cocaína.

A Lei Federal n. 5.449 de 1968, integra o Município de Benjamin Constant à Área de Segurança Nacional sob o Comando de Fronteira do Solimões. A Lei n. 6.634, de 2 de maio de 1979, dispõe sobre a Faixa de Fronteira. Esta Lei considera Faixa de Fronteira, área indispensável à segurança nacional, a faixa de $150 \mathrm{Km}$ (Cento e cinquenta quilômetros) de largura, paralela à linha divisória terrestre do território nacional.

Benjamin Constant é uma área de segurança de fronteira em paralelo ao limite internacional a cidade do Peru e da Colômbia, cuja localização apresenta maior ocorrência de fluxos transfronteiriços, por isso uma maior intensificação de controle e segurança, devido suas características geopolíticas de área de fronteira política e econômica.

A fronteira norte do Brasil identifica-se com as cidades do Alto Solimões, localizada na Mesorregião do Sudoeste Amazonense é atualmente composta de nove municípios. Atalaia do Norte, Tabatinga, Benjamin Constant, São Paulo de Olivença, Amaturá, Santo Antônio de Içá, Tonantins, Jutaí, Fonte Boa. Segundo o Ministério Público do Estado do Amazonas (2011), o Alto Solimões “ tem um área geográfica de 213.281.129 km2 e uma população de 245.047 habitantes” (p. 5). 
Desses municípios, juntamente com Benjamin Constant, fazem parte do limite internacional da faixa de fronteira, as cidades de Atalaia do Norte, Tabatinga, São Paulo de Olivença e Santo Antônio de Içá.

A conturbação existente das cidades Benjamin Constant, Tabatinga e Letícia, na Colômbia, mantém, entre si, relações intensas, em especial, nas atividades da ilegalidade, alimentada pela configuração urbana, que forma uma rede urbana de fronteira interligada pelas redes de controle estratégico do Estado através das forças armadas do Exército, da Polícia Federal, Polícia Militar e os inúmeros projetos de vigilância e controle do território, juntamente com a presença do sistema judiciário penal.

Segundo MENEZES (2009), essa aparelhagem do governo federal representou uma centralização governamental que teve um importante papel político na nacionalização do território do Alto Solimões. Em 1969 é instalado o campus avançado da Pontifícia Universidade Católica do Rio Grande do Sul, através do Projeto Rondon. Em 1985 é aprovado pela Presidência da República, em 19 de dezembro, o projeto Calha Norte através da exposição de motivos do desenvolvimento e segurança na região ao norte dos rios Solimões e Amazonas.

A urgência do cumprimento da Lei na forma da Constituição exigiu do Estado e dos Territórios Nacionais um aparelhamento jurídico e militar presente e funcional nas cidades para regular e normatizar a infração e as prerrogativas penais.

Com os direitos e garantias constitucionais relativas aos crimes hediondos, como a prática do racismo, a prática de tortura, o tráfico ilícito de entorpecentes e drogas afins representaram a culminância da simplicidade das ilegalidades.

Com a Constituição de 1989, o Estado brasileiro passa a controlar a cocaína na cidade de Benjamin Constant, essa prerrogativa vai consolidar as relações do poder ecológico na política, na economia e na cultura da sociedade do Alto Solimões. 
Segundo LEONARDI (2000), a acentuação das atividades extrativista da madeira vai levar muitas pessoas a procurar outras atividades, algumas ilegais. Esse momento pode ter contribuído com as atividades do tráfico de cocaína na região. Muitos daqueles que trabalhavam com a madeira tinham conhecimentos suficientes dos rios e igarapés da região do Solimões e Javali, eram os mais apropriados para carregar a cocaína, em especial para Tefé e Manaus.

Segundo LEONARDI (2000), a questão do narcotráfico é muito grave nas fronteiras do Peru e da Colômbia. Sem os inúmeros sócios locais os grandes cartéis da cocaína nunca teriam se implantado na fronteira brasuleira. Também não é uma simples questão moral ou de saúde individual (“droga faz mal para a saúde”), mas uma questão política maior, pois tem efeito corrosivo sobre as instituições estatais, os partidos políticos, a magistratura, a imprensa. Na Colômbia, 30 juízes foram assassinados nos últimos anos por não terem aceitados as ofertas do narcotráfico que envolviam propinas mensais superiores aos salários da magistratura e ameaças constantes de assassinar os familiares. Como essas ameaças quase sempre se concretizaram, fica a constatação da coragem que precisa ter um juiz para ser honesto em Letícia já que um grande número de pessoas, juízes, prefeitos, vereadores, deputados, senadores, policiais, empresários, jornalistas, camponeses participam de uma forma ou outra de colaboração com o crime organizado.

LEONARDI (2000) vê o narcotráfico como um problema grave na fronteira amazônica. $\mathrm{Na}$ sua passagem pelo Alto Solimões pode identificar alguns fatos relacionados ao avanço do narcotráfico. Os segmentos brasileiros do judiciário, administrativo e os políticos estão sendo cada vez mais utilizados pelos cartéis colombianos, inclusive ajuda financeira nas eleições municipais recente. O narcotráfico é um poder paralelo ao do Estado brasileiro, capaz de afetar todos os órgãos e os serviços do governo. As lideranças indígenas têm consciência do perigo que 
representa o narcotráfico. O Conselho Indígena do Vale do Javali (Civaja) tem se preocupado com a existência de pista de pouso clandestina no Vale do Javali e com o aliciamento de indígenas pelos traficantes. Segundo liderança da Pastoral Indigenista da Diocese do Alto Solimões, a região do Alto Solimões e do Vale do Javali estão sendo utilizadas como região de transferência de cocaína da Colômbia para o Brasil. O envolvimento dos traficantes brasileiros da região com os colombianos tem-se manifestado nas eleições municipais de algumas cidades.

LEORNARDI (2000) aponta alguns aspectos geográficos do Trapézio para situar a problemática do tráfico de cocaína em Benjamin Constant. O Rio Iça faz fronteira com a Colômbia pelo rio Putumayo que também é um Departamento da Colômbia. Um dos lugares mais violentos, em guerra civil há mais de 40 anos, envolvido com as guerrilhas, grupo paramilitares, repressão dirigida pelo exército com o apoio norteamericano. Letícia é a capital do Departamento Amazonas da Colômbia, fronteira com a Cidade de Tabatinga. Ligadas pela Avenida da Amizade do lado de Tabatinga. Tabatinga fica a margem esquerda do Solimões. Benjamin Constant fica na margem oposta, no treco em que o Rio Javari encontra-se com o Solimões. As cidades de Tabatinga e de Benjamin Constant estão, portanto situadas nas imediações da região da Amazônia Colombiana. Benjamin Constant está próxima da cidade de São Paulo de Olivença e Santo Antônio de Iça, pelo rio Solimões pode-se chegar até a fronteira colombiana, passando pela povoação de Içacuera e União, chega à currutela de Ipiranga - fronteira com a Colômbia, onde Putumayo entra no Brasil, com pista de pouso para aviões. O Rio Javari é um afluente do Rio Solimões, limite entre o Amazonas e o Peru. Os afluentes do Javari à margem esquerda são os rios peruanos e os da margem direito são os brasileiros, os rios Curuçá e Ituí.

$\mathrm{O}$ avanço da racionalidade da cocaína no século XX na cidade de Benjamin Constant está relacionado à consolidação do mercado 
internacional da cocaína, a estratégia do Regime Militar de modernizar a Amazônia e ao sistema de aviamento advindo do extrativismo da borracha do Alto Solimões que por vez deve absorver o tráfico de cocaína advinda da Amazônia Colombiana.

Em países como a Colômbia, o sistema extrativista passaria às mãos dos narcotraficantes, com plantações intensas de coca e maconha, acentuando ainda mais os métodos de coerção e violência contra os trabalhadores e as populações da região afetada (SOUZA, p. 298).

A racionalidade ecológica da cocaína é contemporânea da chegada das grandes empresas capitalistas transnacionais de minério, petróleo e agropecuária, empreendimentos que dão uma forma nova ao sistema de aviamento com o pano de fundo do desenvolvimento sustentável, modernização e preservação da Amazônia, mas de fato o alvo primeiro das relações de poder é o controle do mercado de cocaína, uma das principais matéria-prima do trapézio amazônico.

O mercado internacional da cocaína vai desenvolver a produção da folha de coca em grande escala, enriquecendo as elites das cidades da fronteira do Brasil, da Colômbia e do Peru, substituindo a agricultura de subsistência da folha da coca pela produção, transformação e transporte da cocaína, principal causa da criminalidade nas cidades de Benjamin Constant, Tabatinga e Letícia.

Segundo PALACIO (2009), Letícia viveu o auge prospero do comércio da cocaína na década de 1980. A sedução econômica dos lucros provenientes do tráfico de cocaína tornou-se uma oportunidade para a população da elevação do padrão de vida, "a despeito de qualquer reprovação moral, o mais rentável trabalho a se dedicar" (RORIGUES, 2003, 51).

A presença militar colombiana tem dificultado a dinâmica do mercado da cocaína. O poder que se formou em parte na Amazônia 
brasileira, com o regime militar, tem uma peculiaridade com as forças armadas colombianas quando se trata do combate ao narcotráfico.

Leticia se converte em um lugar de treinamento da força militar para controlar os territórios dos rios amazônicos, como o Putamayo (Iça) e o Caquetá (Japurá). Esta situação pode adquirir novos matizes de impacto internacional si a base militar americana de Manta seja retirada do Equador e seja eventualmente substituída pela nova que será construída em Leticia ( $p$, 154).

O poder ecológico torna-se cada vez mais microfísico quanto mais avança o mercado da cocaína na vida da população da cidade, passando da Lei à sedução do dinheiro, a venda da cocaína entra nas cidades da Amazônia pelas mãos de uma população que não se cansa de fazer frente ao avanço das forças armada na fronteira amazônica.

Com a ampliação do mercado da cocaína, cresce também a demanda. A cocaína vai ser a nova seiva branca da Amazônia, agora muita elástica e globalizada e com um poder de sedução maior do que a antiga borracha da selva amazônica. Ela traz de volta aquela ostentação dos velhos barões do extrativismo. Seduzidos pelos altos lucros, os agricultores sem receios com as consequências legais começam a cultivar a folha da coca.

As cidades de fronteira vão viver um momento de ostentação com o crescimento do mercado de cocaína. Juntamente com a ostentação das elites endinheirada, cresce também a criminalidade nos espaços urbanos, rurais institucionais, nas administrações locais, nas prefeituras e delegacias diante do "lucro fácil" fazem vista grossa, outros são subornados e corrompidos. As próprias forças armadas e as forças policiais que tinham por missão o controle do comércio ilegal da cocaína, uma parcela é seduzida pelos lucros generalizados e logo constituem uma criminalidade paralela. Portanto, a instituição que tinha por missão conter a criminalidade, agora ela passa a comandar e controlar a criminalidade. 
A facilidade de lucros altos e generalização dos ganhos, que não discriminavam ninguém, envolveram todo o tecido social e o caráter da sociedade extrativista tradicional. A ostentação voltou a ser moda, assim como a corrupção e o suborno foram á normas da administração local. Comerciantes, fazendeiros, oficiais do exército, policiais, administradores, todos tiveram sua parte" (SOUZA, p. 299).

É provável que a abrangência do negócio tenha suplantado o comércio da madeira e tenha submetido à ilegalidade uma população ainda recente, tornando o delito de tráfico de drogas o carro chefe na estatística criminal no Estado do Amazonas e com o acréscimo da lógica de ferro do sistema carcerário constituiu-se uma parcela significante da sociedade em grupo de risco e de difícil retorno da exclusão social.

O próspero mercado da cocaína na Amazônia tem ampliado a partir da década de 70. Segundo CASTELLS (2003), o crescimento da indústria de drogas "tem transformado a economia e a política da América Latina" (p. 241). Essa indústria concentra-se "principalmente na produção, processamento e exportação de coca e cocaína” (p. 243).

Para além do tráfico de drogas, o mercado da cocaína tem ampliado sua atividade para outras práticas criminosas, como a lavem de dinheiro, que se visível nas transações bancárias das cidades de fronteira, contrabando, tráfico de armas e de pessoas. Segundo CASTELLS (2003), a rede criminosa que se instalou pelo mercado da cocaína tem "constituído um mundo vasto e complexo, cuja estrutura altamente descentralizada permeia todas as sociedades latino-americanas e nelas imprime a sua marca" (p. 243).

As poderosas redes criminosas do mercado de drogas abalam os clássicos paradigmas do desenvolvimento e da dependência, teoria sustentada pelos estudiosos da Amazônia, abrindo espaço para a recente 
interpretação da sustentabilidade que está relacionado com o modo de vida das pessoas que moram nas cidades interior da Amazônia.

Finalizo o texto com a problemática da criminalização do tráfico de cocaína.

O Encontro Interinstitucional sobre a Ação da Justiça na Tríplice Fronteira organizado pelo Ministério Público do Estado do Amazonas realizado em Manaus no dia 28 de outubro de 2011tem clareza de que os problemas enfrentados no Trapézio amazônico em relação à cidadania, segurança pública, violência e criminalidade não podem ser enfrentados sem a participação de conjunto de todas as entidades públicas, tendo em vista uma política pública integral que componha as esferas da saúde, educação, trabalho e meio ambiente, para além do simples combate da criminalidade da cocaína.

A política de controle da cocaína na visão do Ministério Público do Amazonas (2011) deve se basear na prática social da intersetorialidade de enfrentamento dos problemas da fronteira norte do Brasil que implica em forma de administrar, de governar e de molda políticas públicas "capazes de agregar todo potencial cooperativo das estruturas sociais e institucionais em prol dos objetivos definidos de segurança e de justiça" (Ministério Público do Estado do Amazonas, 2011, p.4).

A política penal de controle da cocaína não pode está centrada na proteção e repressão de exclusividade militar e policial, mas deve estar articulada em termos de prevenção, assistência e à minimização dos danos e à eliminação dos riscos, tendo em vista que o tráfico de cocaína na fronteira composta uma multiplicidade de agentes, causas de risco e perigos que subvertem o paradigma da política criminal que pensa a segurança pública em termos de polícia, justiça, sistema prisional que apenas parcialmente pode influenciar os índices de criminalidade relacionados ao crime organizado da cocaína. 
Segundo o Ministério Público do Estado do Amazonas (2011), a complexa rede de tráfico internacional de cocaína tem sua base na cidade de Tabatinga, "local onde são feitas as negociações para o recebimento e remessa de drogas, bem como de onde são canalizados recursos financeiros para serem "branqueados", numa espécie de mercado financeiro da droga" (p. 6). Podemos dizer que Tabatinga é a porta de entra de $70 \%$ de cocaína na fronteira norte.

O tráfico de drogas, problema endêmico e crônico no chamado trapézio amazônico, com a sua cada vez mais poderosa vertente internacional e seus tentáculos transnacionais, supera os limites do direito penal nacional. Afeta aspectos básicos e essenciais da vida como saúde, violência, corrupção, micro e macrocriminalidade, deterioração social etc. (p.6).

\section{Referências}

ARAÚJO, André Vidal. Introdução à Sociologia do Amazonas. Manaus: Editora Valer, 2003.

CASTELLS, Manuel. Narcotráfico, Desenvolvimento e Dependência na América Latina. IN: O Fim do Milénio. Trad. Alexandra Figueiredo e Rita Espanha. Lisboa: Fundação Calouste Gulbenkian, 2003.

COSTA, Kelerson Semerene. Apontamos sobre a formação histórica da Amazônia: uma abordagem continental. Série Estudos e Ensaios/Ciências sociais/ FLACSOBrasil - junho/2009. http://www.flacso.org.br.

Encontro Interinstitucional sobre a Ação da Justiça na Tríplice Fronteira. Ministério Público do Estado do Amazonas - Procuradoria Geral da Justiça. Manaus, 2011.

Disponível

em:

HTTP://www.mpam.mp.br/index.php/noticias/destaque-noticias/24

FERREIRA \& MARTINI. Cocaina: lendas, história e abuso. Rio Grande do Sul: Revista Brasileira de Psiquiatria, 2001; 23(2):96-97. http://www.scielo.br/pdf/rbp/v23n2/5583.pdf.

FOUCAULT, Michel. A “Governamentalidade”. IN: Estratégia, Poder-Saber. Ditos \& escritos IV. Rio de Janeiro: Forense Universitária, 2003. 
História da Sexualidade - A Vontade de Saber. Trad. Maria Thereza da Costa Albuquerque e J.A.Guilon Albuquerque. 10 ed. Rio de Janeiro: Graal, 1988.

Nascimento da Biopolítica - Curso dado no Collége de France (1978-1979). T. Eduardo Brandão. São Paulo: Martins Fontes, 2008.

Vigiar e Punir. História da Violência nas Prisões. Petrópolis: Vozes, 2010.

O Anormal - Curso no Collège de France (1974-1975). Trad. Eduardo Brandão. São Paulo: Martins Fontes, 2002.

Em Defesa da Sociedade. Trad. Maria Ermantina Galvão. São Paulo: Martins Fontes, 2005.

JOBIM, Anisio. Panoramas Amazônicos. VI - Benjamin Constant. ManausAmazonas, 1943.

1940.

Panoramas Amazônicos. V-São Paulo de Olivença. Manaus-Amazonas,

LEORDARDI, Victor. Fronteiras Amazônicas do Brasil: Saúde e História Social. Brasília: Paralelo 15; São Paulo: Marco Zero, 2000.

MALETTE, Sébastien. Foucault para o próximo século: ecogovernamentalidade. São Paulo: Revista Ecopolítica, 1: 4-25, 2011. www.revista.pucsp.br/ecopolítica.

MELLO, Octaviano. Benjamin Constant. In: Topônimos Amaz̧onenses. Edições Governo do Estado do Amazonas: Manaus, 1967.

MENEZES, Maria Lucia Pires. Pequenas cidades em Faixa de fronteira na Amazônia: o caso de Tabatinga e Benjamin Constant. In: Cidades Brasileiras. $V$. l - Territorialidades, sustentabilidade e demandas sociais. Org. José Aldemir de Oliveira. Manaus: Edua, 2009.

NIETZSCHE. Para a Genealogia da Moral. Um Escrito Polêmico em Adendo a "Para Além do Bem e do Mal. São Paulo: Nova Cultural, 1991.

PALACIO, Germán. Leticia y El corazón de Suramérica: una urbe em la Triple Frontera Amazonica. In: Cidades na Floresta. org. Edna Castro. São Paulo: Annablume, 2009.

PASSET'TI, Edison. Ecopolitica: o que pode um corpo? IN: Nietzsche e Deleuze: que pode o corpo. Rio de Janeiro: Relume Dumará, 2002.

SOUZA, Márcio. A Historia da Amazônia. Manaus: Editora Valer, 2009. 